\title{
Minor Anomalies: Can They Predict Specific Major Defects? A Study Based on 23 Major and 14 Minor Anomalies in Over 25,000 Newborns with Birth Defects
}

\author{
Hebe Campaña, PhD, ECLAMC ${ }^{1}$ Monica Rittler, PhD, ECLAMC ${ }^{2}$ Fernando A. Poletta, PhD, ECLAMC ${ }^{3}$ \\ Juan Antonio Gili, Lic, ECLAMC ${ }^{3}$ Mariela Soledad Pawluk, Lic, ECLAMC ${ }^{1}$ \\ Sandra Constanza Scala, S, ECLAMC ${ }^{1}$ Jorge Santiago López Camelo, PhD, ECLAMC ${ }^{1,3}$ \\ ${ }^{1}$ Multidisciplinary Institute of Cellular Biology (IMBICE), La Plata, \\ Argentina \\ 2 Hospital Materno Infantil Ramón Sardá, University of Buenos Aires, \\ Argentina \\ ${ }^{3}$ Center for Medical Education and Clinical Research (CEMIC), Buenos \\ Aires, Argentina \\ Am J Perinatol 2014;31:447-454.

\begin{abstract}
Address for correspondence Jorge S. López Camelo, PhD, ECLAMC, Hospital Universitario CEMIC, Galván 4102 (C1431FWO) Buenos Aires, Argentina (e-mail: jslc@eclamc.org).
\end{abstract}

\begin{abstract}
Keywords

- epidemiology

- minor anomalies

- predictors

- birth defects

- associations

Background Minor anomalies (mAs) are morphological features with little clinical relevance that have been mentioned as possible predictors of major defects (MDs).

Objectives To identify the preferential associations between selected MDs and mAs and to establish if $\mathrm{mAs}$ can serve as predictors for specific MDs.

Study Design Information of newborns with birth defects was obtained from the ECLAMC (Latin American Collaborative Study of Congenital Malformations) database. The sample consisted of 27,247 live- and stillborn newborns with multiple malformations that included at least one of the selected MDs or mAs. The odds ratio and predictive values were calculated for significant associations, and concurrence rates in first degree relatives.

Results A total of 33 significant minor-major associations were identified. Single umbilical artery (SUA) and preauricular tags were the most frequent $\mathrm{mAs}$; the former was associated with $10 \mathrm{MDs}$, the latter only with microtia. The highest positive predictive value was shown by SUA for anal atresia. Newborns with preauricular tags had significantly more relatives with microtia than expected.

Conclusions No new relevant associations between MDs and $\mathrm{mAs}$ were identified and few $\mathrm{mAs}$ seem to serve as predictors for specific MDs in the same newborn. However, preauricular tags can predict the occurrence of microtia in other family members.
\end{abstract}

A congenital minor anomaly $(\mathrm{mA})$ can be defined as a morphological feature with little or no medical or cosmetic importance and that it is present in less than $4 \%$ of the general population., ${ }^{1,2}$

Although mAs occur primarily as isolated findings, their frequency is much higher in newborns with major defects.
Newborn population studies have shown that the greater the number of $\mathrm{mAs}$, the higher the risk for a coexisting major defect. ${ }^{1,3,4}$ Therefore, mAs have been mentioned as possible predictors of major underlying defects or syndromes and as tools to identify teratogens. ${ }^{5}$ received

March 21, 2013

accepted after revision

June 14, 2013

published online

August 21, 2013
Copyright $\odot 2014$ by Thieme Medical Publishers, Inc., 333 Seventh Avenue, New York, NY 10001, USA. Tel: +1(212) 584-4662.
DOI http://dx.doi.org/ 10.1055/s-0033-1351660. ISSN $0735-1631$. 
Published studies have either focused on the previously mentioned correlation between the number of $\mathrm{mAs}$ and their ability to predict major defects or have referred to a single specific minor-major anomaly association. ${ }^{6-8}$ To our knowledge, however, no reports have searched for specific associations between selected minor and major birth defects, nor have they examined predictive values.

The aims of the present work were to identify preferential associations between selected minor and major anomalies, and, by analyzing possible reasons for their coexistence, to establish if mAs can serve as predictors for specific major defects.

This study involved a series of newborns with birth defects, diagnosed in the ECLAMC (Spanish acronym for Latin American Collaborative Study of Congenital Malformations) maternity hospitals network. ${ }^{9}$

\section{Methods}

In this work, the term " $\mathrm{mA}$ " was applied to any morphological feature with little medical importance, according to the above mentioned definition. No distinction was made between $\mathrm{mAs}$ proper, that is, those arising during phenogenesis, and minor malformations, that is, those arising during embryogenesis. ${ }^{10,11}$

A total of 23 major and $14 \mathrm{mAs}$ were selected, based on their conspicuity and ascertainment reliability (Appendix).

Two samples of newborns with birth defects, ascertained among 5,587,954 births between 1967 and 2007 in 253 maternity hospitals were obtained from the ECLAMC database. The first sample consisted of 27,247 live- and stillborn newborns with multiple anomalies, including at least one of the selected major and/or minor defects. This sample was used to calculate association risks and predictive values of $\mathrm{mAs}$ for their associated major defects and to describe clinical features of newborns with preferential associations.

The second sample of 74,763 live- and stillborn newborns with each one of the selected minor or major anomalies as a single defect was obtained with the sole purpose of establishing concurrence rates in first degree relatives.

Newborns with or without recognized syndromes or sequences were included.

The odds ratio (OR) of the 322 possible combinations of one minor and one major selected defects (dyads) were determined. (A dyad represents the combination of two specific defects, with or without other defects present in the same newborn.)

As the purpose was to identify preferential associations regardless of their sample size, the magnitude of the association risks was used as a selection criterion, rather than statistical significance. Dyads with OR values above the 90th percentile were included and further analyzed (selected dyads).

Clinical features of the newborns with the selected dyads were compared with those of reference newborns. The latter were defined as newborns who had a major defect and any other anomaly except the $\mathrm{mA}$ of each respective dyad. The differences were evaluated with a $t$-test or a chi-squared test for continuous and categorical variables, respectively.

Positive predictive values (the proportion of cases with the major defect among the total number of cases with the
Appendix Total number of newborns with the selected major and minor defects

\begin{tabular}{|l|l|l|}
\hline 23 Major selected defects & $\begin{array}{l}\text { ASSO } \\
22124\end{array}$ & $\begin{array}{l}\text { ISO } \\
43964\end{array}$ \\
\hline Omphalocele & 856 & 633 \\
\hline Gastroschisis & 190 & 984 \\
\hline Anencephaly & 972 & 2742 \\
\hline Spina bifida & 1798 & 2680 \\
\hline Hydrocephaly & 1975 & 2633 \\
\hline Cephalocele & 519 & 683 \\
\hline Microtia & 1126 & 1494 \\
\hline Cleft lip & 386 & 1601 \\
\hline Cleft lip and palate & 1548 & 3416 \\
\hline Cleft palate & 1382 & 964 \\
\hline Esophageal atresia & 896 & 776 \\
\hline Anal atresia & 1596 & 912 \\
\hline Truncus arteriosus & 594 & 1242 \\
\hline ASD & 579 & 454 \\
\hline VSD & 1161 & 2504 \\
\hline Severe hypospadias & 438 & 1962 \\
\hline Postaxial polydactyly & 1480 & 7915 \\
\hline Preaxial polydactyly & 399 & 1268 \\
\hline Transverse LR & 785 & 782 \\
\hline Preaxial LR & 495 & 148 \\
\hline Diaphragmatic hernia & 546 & 811 \\
\hline Pectoralis agenesis & 199 & 110 \\
\hline Down syndrome & 2204 & 7250 \\
\hline Sis & \\
\hline
\end{tabular}

Abbreviations: ASD, atrial septal defect; ASSO, associated; ISO, isolated; LR, limb reduction; VSD, ventricular septal defect.

\begin{tabular}{|l|l|l|}
\hline 14 Minor selected anomalies & $\begin{array}{l}\text { ASSO } \\
\mathbf{6 8 6 1}\end{array}$ & $\begin{array}{l}\text { ISO } \\
\mathbf{3 0 7 9 9}\end{array}$ \\
\hline Angiomas flat & 972 & 5491 \\
\hline Angiomas cavernous & 72 & 778 \\
\hline Neonatal teeth & 219 & 556 \\
\hline Inguinal hernia & 122 & 106 \\
\hline Umbilical hernia & 199 & 2035 \\
\hline Preauricular tags & 2135 & 12288 \\
\hline Preauricular pits & 947 & 4536 \\
\hline Asymmetric cry & 102 & 195 \\
\hline Single umbilical artery & 939 & 1023 \\
\hline Hydrocele & 194 & 339 \\
\hline Foot 2-3 syndactyly & 296 & 571 \\
\hline Extra nipples & 473 & 2306 \\
\hline Cutaneous tags not preauricular & 130 & 553 \\
\hline Macrosomia & 61 & 22 \\
\hline
\end{tabular}

Abbreviations: ASSO, associated; ISO, isolated.

Note: Macrosomia, verbatim report by the pediatrician, as a categorical feature. 
corresponding $\mathrm{mA}$ ) were obtained for each dyad. To establish possible biological relationships between components of the dyads, the concurrence rates in first-degree relatives were obtained (i.e., one defect of the dyad present in the index case and the other present in his/her relative) for dyads with sufficient specified data for affected relatives. For this step, the sample consisted of newborns who presented the major or $\mathrm{mA}$ of each selected dyad as a single defect. For each of these newborns, the number of firstdegree relatives (parents and siblings) affected with the other anomaly of the corresponding dyad was obtained from the database. For all analyzed dyads, the rates of affected parents did not differ from rates of affected siblings; therefore, parents and siblings were collapsed into a single category (first-degree relatives) for each dyad. The expected numbers of affected relatives were calculated using the total number of first-degree relatives of index cases and the ECLAMC birth prevalence rate for each anomaly among isolated cases.

Observed/expected rates were obtained and significance levels set at 1 and 5\% according to a Poisson distribution.

\section{Results}

A total of 33 dyads with OR values above the 90th percentile were included for further analysis.

\section{Clinical Features}

The most frequently observed mAs were preauricular tags and SUA. SUA was part of 10 dyads, while preauricular tags were only associated with microtia.

All 10 dyads involving SUA showed high mortality rates, and in seven, birth weights were significantly lower than their reference values (-Table $\mathbf{1}$ ).

Ambiguous genitalia were more frequent in newborns with the dyads SUA + anorectal atresia or SUA + microtia than in reference newborns.

Higher birth weights were observed for the dyads involving microtia, except when associated with SUA where birth weight was significantly lower. Newborns with microtia and SUA had more associated anomalies than those without SUA (-Fig. 1).

Newborns with microtia + tags showed significantly lower death rates and higher birth weights than reference newborns, and fewer associated anomalies than newborns with microtia without tags (-Fig. 2)

Male and female newborns were almost equally distributed among the 33 selected dyads, and no difference in twinning rates was observed between newborns with the selected dyads and reference newborns.

\section{Odds Ratio and Positive Predictive Values}

The positive predictive values and OR of $m A$ s for the major defect of each dyad are shown in - Table 2. SUA showed a 3.5fold risk for anal atresia and the highest positive predictive value ( $17 \%$ of newborns with SUA had anal atresia vs. $5.5 \%$ of newborns without SUA), followed by macrosomia, with a 6 -fold risk for omphalocele. About $16 \%$ of newborns with macrosomia had omphalocele (vs. 3\% of newborns without macrosomia).

\section{Concurrence Rates in First-Degree Relatives}

Microtia + preauricular tags was the only dyad with a large enough sample size to allow calculation of concurrence rates. Newborns with preauricular tags (as a single defect) had significantly more than expected first-degree relatives with microtia. Inversely, newborns with microtia had significantly more than expected relatives with preauricular tags (-Table 3 ).

\section{Discussion}

The usefulness of mAs as indicators of more severe underlying pathological conditions has often been mentioned, although a common issue has always been the methodological difficulties involved in consistently recognizing, describing, reporting, and classifying $\mathrm{mAs},{ }^{5}$ which has hindered adequate comparisons among reports.

For instance, Marden et $\mathrm{al}^{1}$ reported that newborns with three or more mAs had a $90 \%$ chance of having a major defect, while Leppig et $\mathrm{al}^{4}$ who used an examination protocol which increased the number of identified $\mathrm{mAs}$ and normal variants, reported a $20 \%$ risk.

Furthermore, mAs have been variably defined in the literature. ${ }^{1-3}$ Opitz ${ }^{10}$ has divided them into mild malformations, that is, "all or none defects" (defects of organogenesis) and $\mathrm{mAs}$, that is, quantitative traits (defects of phenogenesis), while normal variants are mAs with a higher than expected incidence because of their familial or ethnic background. For instance, simian crease has a $17 \%$ incidence in Chinese populations, $^{12}$ against approximately $2 \%$ in Caucasians. ${ }^{3}$

While mild malformations, such as preauricular tags or extra nipples, are easily recognized and therefore reliably reported, quantitative traits, such as hypertelorism, depend on measurements and are therefore more susceptible to overor underreporting. However, most authors have included continuous traits among the analyzed physical features, ${ }^{1,4}$ and it is doubtful that different examiners would apply equal criteria when defining them as anomalous or not. This variation was demonstrated by Holmes et $\mathrm{al}^{5}$ who analyzed the interexaminer agreement in identifying minor physical features in newborns and found that in $75 \%$ of cases, the interexaminer agreement was poor.

\section{Strengths and Weaknesses}

Most limitations of this work are common to studies dealing with $\mathrm{mAs}$, for instance, their possible underascertainment. Although ECLAMC procedures require a complete description and report of major and $m A s$, the description of some $m A s$ might have been omitted in newborns with multiple major defects.

Overascertainment of mAs may also have existed. When an association is well known, such as SUA + anal atresia, clinicians may be more likely to search for the $\mathrm{mA}$ in newborns with the major defect. 
Table 1 Clinical features of cases showing the 33 significant associations between a major defect and a minor anomaly

\begin{tabular}{|c|c|c|c|c|c|c|c|}
\hline \multicolumn{2}{|l|}{ Dyads } & \multicolumn{6}{|c|}{ Clinical features } \\
\hline Major defect & Minor anomaly & $N$ & BW (Mean \pm SD) & Male $(n)$ & AG $(n)$ & Mortality (n) & $\mathrm{T}(n)$ \\
\hline \multirow[t]{3}{*}{ Omphalocele } & SUA & 50 & $2001.4 \pm 874.6$ & 26 & 5 & 33 & 0 \\
\hline & Macrosomia & 10 & $4405.6 \pm 563.3^{a}$ & 2 & 0 & 2 & 0 \\
\hline & Other & 796 & $2101.4 \pm 949.3$ & 381 & 127 & 567 & 32 \\
\hline \multirow[t]{2}{*}{ Gastroschisis } & SUA & 11 & $1914.5 \pm 855.1$ & 2 & 3 & 7 & 1 \\
\hline & Other & 179 & $2043.3 \pm 650.7$ & 88 & 18 & 90 & 2 \\
\hline \multirow[t]{4}{*}{ Hydrocephaly } & Inguinal hernia & 11 & $2372.5 \pm 1163.5$ & 10 & 0 & 6 & 0 \\
\hline & SUA & 80 & $2172.2 \pm 1041.1^{\mathrm{a}}$ & 46 & 3 & 50 & 1 \\
\hline & Macrosomia & 7 & $4338.6 \pm 445.8^{a}$ & 5 & 0 & 1 & 0 \\
\hline & Other & 1878 & $2626.6 \pm 990.4$ & 1039 & 46 & 920 & 62 \\
\hline \multirow[t]{3}{*}{ Cephalocele } & Angioma & 2 & $2840.0 \pm 1187.9$ & 0 & 0 & 1 & 0 \\
\hline & Inguinal hernia & 3 & $2096.6 \pm 859.6$ & 3 & 0 & 3 & 0 \\
\hline & Other & 514 & $2347.9 \pm 920.5$ & 224 & 28 & 351 & 14 \\
\hline \multirow[t]{5}{*}{ Microtia } & SUA & 48 & $2014.5 \pm 807.2^{\mathrm{a}}$ & 16 & $7^{a}$ & 34 & 0 \\
\hline & Preauricular pits & 47 & $3076.2 \pm 633.0^{a}$ & 21 & 0 & $4^{a}$ & 0 \\
\hline & Preauricular tags & 246 & $2972.0 \pm 627.4^{\mathrm{a}}$ & 134 & 1 & $26^{a}$ & 5 \\
\hline & Asymmetric cry & 12 & $2997.5 \pm 473.4^{\mathrm{a}}$ & 7 & 0 & 2 & 0 \\
\hline & Other & 773 & $2395.8 \pm 807.2$ & 430 & 19 & 378 & 23 \\
\hline \multirow[t]{2}{*}{ ASD } & Macrosomia & 3 & $4251.7 \pm 276.1^{a}$ & 2 & 0 & 0 & 0 \\
\hline & Other & 576 & $2655.1 \pm 835.3$ & 281 & 12 & 166 & 12 \\
\hline \multirow[t]{3}{*}{ VSD } & SUA & 49 & $1921.5 \pm 779.4^{a}$ & 21 & 1 & $24^{b}$ & 1 \\
\hline & Foot 2-3 syndactyly & 15 & $2334.0 \pm 792.6$ & 5 & 0 & 5 & 1 \\
\hline & Other & 1097 & $2527.1 \pm 842.6$ & 526 & 14 & 315 & 24 \\
\hline \multirow[t]{4}{*}{ Truncus arteriosus } & Inguinal hernia & 4 & $2105.0 \pm 616.7$ & 3 & 0 & 1 & 0 \\
\hline & Asymmetric cry & 7 & $3022.9 \pm 884.7^{b}$ & 1 & 0 & 1 & 0 \\
\hline & SUA & 34 & $2361.5 \pm 1056.1$ & 15 & 0 & 14 & 1 \\
\hline & Other & 549 & $2508.3 \pm 791.9$ & 280 & 15 & 181 & 19 \\
\hline \multirow[t]{2}{*}{ Cleft palate } & Neonatal tooth & 13 & $2986.9 \pm 829.6^{b}$ & 7 & 0 & 3 & 0 \\
\hline & Other & 1369 & $2556.5 \pm 847.1$ & 602 & 40 & 549 & 25 \\
\hline \multirow[t]{2}{*}{ Cleft lip } & Tags other & 3 & $2480.0 \pm 1301.8$ & 3 & 0 & 1 & 0 \\
\hline & Other & 383 & $2429.2 \pm 1000.5$ & 175 & 9 & 176 & 12 \\
\hline \multirow[t]{2}{*}{ Esophageal atresia } & SUA & 89 & $1928.6 \pm 744.5^{a}$ & 39 & 8 & 56 & 3 \\
\hline & Other & 807 & $2164.0 \pm 769.0$ & 424 & 39 & 459 & 25 \\
\hline \multirow[t]{2}{*}{ Anal atresia } & SUA & 160 & $2018.7 \pm 814.0^{\mathrm{a}}$ & 70 & $54^{b}$ & 108 & 5 \\
\hline & Other & 1436 & $2350.6 \pm 844.0$ & 710 & 333 & 784 & 68 \\
\hline \multirow[t]{4}{*}{ Hypospadias } & Angioma & 2 & $1650.0 \pm 0.0$ & 2 & 0 & 0 & 0 \\
\hline & Inguinal hernia & 6 & $1518.3 \pm 816.1^{b}$ & 6 & 0 & 0 & 0 \\
\hline & Hydrocele & 15 & $3242.0 \pm 996.2^{a}$ & 15 & 0 & 0 & 2 \\
\hline & Other & 415 & $2513.9 \pm 875.1$ & 397 & 17 & 84 & 12 \\
\hline \multirow[t]{2}{*}{ Transverse limb reduction } & Foot 2-3 syndactyly & 23 & $2690.0 \pm 810.5$ & 11 & 0 & 5 & 0 \\
\hline & Other & 762 & $2447.5 \pm 946.9$ & 389 & 37 & 270 & 31 \\
\hline \multirow[t]{3}{*}{ Preaxial limb reduction } & Foot 2-3 syndactyly & 9 & $1952.2 \pm 764.5$ & 5 & 0 & 4 & 0 \\
\hline & SUA & 43 & $1868.8 \pm 709.7^{b}$ & 22 & 2 & 24 & 3 \\
\hline & Other & 443 & $2122.3 \pm 911.4$ & 252 & 24 & 236 & 10 \\
\hline
\end{tabular}


Table 1 (Continued)

\begin{tabular}{|c|c|c|c|c|c|c|c|}
\hline \multicolumn{2}{|l|}{ Dyads } & \multicolumn{6}{|c|}{ Clinical features } \\
\hline Major defect & Minor anomaly & $N$ & BW (Mean \pm SD) & Male $(n)$ & AG (n) & Mortality (n) & $\mathrm{T}(n)$ \\
\hline \multirow[t]{3}{*}{ Postaxial polydactyly } & Neonatal tooth & 14 & $2812.9 \pm 511.7$ & 9 & 0 & 6 & 1 \\
\hline & Foot 2-3 syndactyly & 30 & $2853.4 \pm 759.0$ & 16 & 1 & $2^{a}$ & 0 \\
\hline & Other & 1436 & $2781.1 \pm 854.8$ & 794 & 35 & 505 & 29 \\
\hline \multirow[t]{2}{*}{ Preaxial polydactyly } & Foot 2-3 syndactyly & 11 & $2565.9 \pm 1069.5$ & 4 & 0 & 3 & 1 \\
\hline & Other & 388 & $2787.8 \pm 826.8$ & 225 & 9 & 82 & 5 \\
\hline \multirow[t]{3}{*}{ Diaphragmatic hernia } & SUA & 33 & $1862.3 \pm 749.6^{a}$ & 14 & 2 & 26 & 1 \\
\hline & Macrosomia & 2 & $3120.0 \pm 28.3$ & 1 & 0 & 1 & 0 \\
\hline & Other & 511 & $2343.1 \pm 890.4$ & 250 & 23 & 400 & 7 \\
\hline
\end{tabular}

Abbreviations: AG, ambiguous genitalia; ASD, atrial septal defect; BW, birth weight; N, number of cases for each dyad; SUA, single umbilical artery; T, twins; VSD, ventricular septal defect.

Note: Mortality, stillborn + neonatal death (live born dead at discharge).

${ }^{\mathrm{a}} \mathrm{p}<0.01$.

${ }^{\mathrm{b}} \mathrm{p}<0.05$.

Memory bias is a recognized weakness when data are obtained through maternal interviews. Although only firstdegree relatives were considered, information about $\mathrm{mAs}$ in relatives could have been subject to such a bias, and it is in fact expected for anomalies such as SUA. However, this bias would result in an underestimation of concurrence rates, and the actual values would be higher than the values obtained in this study.

A further limitation was that all data were obtained from a coded database. Codes often lack the necessary specificity when compared with verbatim descriptions, and when, in addition, data are retrospectively obtained from databases, no measures can be taken to improve the outcome, for instance, by reducing the number of not sufficiently specified defects in affected relatives.

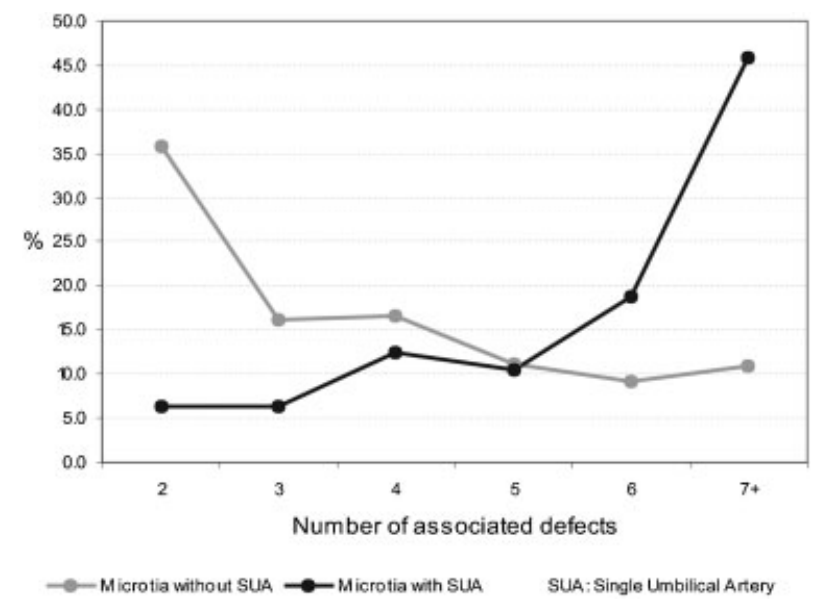

Fig. 1 Associated defects in newborns with microtia with and without single umbilical artery.
Several major anomalies, for example, kidney defects, were not selected because of their uncertain detection rate. Therefore, some significant associations might have remained undetected, and this could explain why only few relevant predictors were identified.

As one of the objectives of the present study was to establish preferential associations between minor and major defects, only dyads were analyzed. Correlations between the number of $\mathrm{mAs}$ and the risk for major defects were not obtained.

The main strengths of the present work were related to the size of the ECLAMC database and to the selection of only categorical (presence/absence) $\mathrm{mAs}$, thereby reducing a possible over- or underreporting.

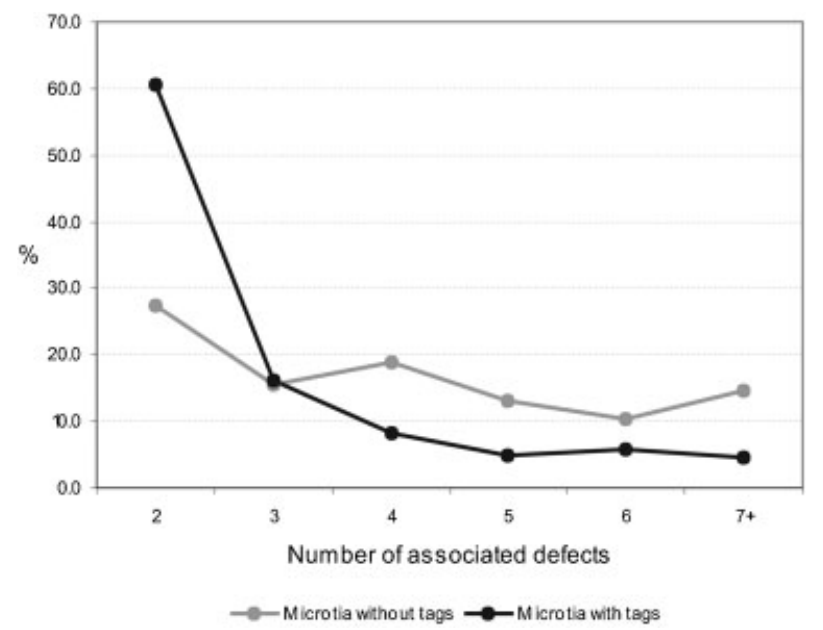

Fig. 2 Associated defects in newborns with microtia with and without tags. 
Table 2 Odds ratios and positive predictive values of the minor anomaly for the major defect of each dyad

\begin{tabular}{|c|c|c|c|c|}
\hline Minor anomaly (m) & Major defect (M) & $M+m$ & $M-m$ & OR (95\% Cl) \\
\hline Macrosomia & Omphalocele & 16.39 & 3.11 & $6.10(3.09-12.07)$ \\
\hline Hydrocele & Hypospadias & 7.77 & 1.56 & $5.31(3.11-9.06)$ \\
\hline Preauricular tag & Microtia & 11.52 & 3.50 & 3.58 (3.09-4.16) \\
\hline SUA & Anal atresia & 17.04 & 5.46 & $3.56(2.98-4.25)$ \\
\hline Asymmetric cry & Truncus arteriosus & 6.86 & 2.16 & $3.33(1.54-7.21)$ \\
\hline SUA & Esophageal atresia & 9.48 & 3.07 & $3.31(2.63-4.16)$ \\
\hline Inguinal hernia & Hypospadias & 4.92 & 1.59 & $3.20(1.40-7.30)$ \\
\hline Asymmetric cry & Microtia & 11.76 & 4.10 & $3.12(1.70-5.71)$ \\
\hline Foot 2-3 syndactyly & Transverse limb reduct. & 7.77 & 2.83 & $2.90(1.88-4.46)$ \\
\hline SUA & Preaxial limb reduction & 4.58 & 1.72 & 2.75 (1.99-3.78) \\
\hline Foot 2-3 syndactyly & Preaxial polydactyly & 3.72 & 1.44 & $2.64(1.43-4.87)$ \\
\hline Macrosomia & ASD & 4.92 & 2.12 & $2.39(0.75-7.65)$ \\
\hline Foot 2-3 syndactyly & Postaxial polydactyly & 10.14 & 5.38 & $1.98(1.35-2.90)$ \\
\hline SUA & Diaphragmatic hernia & 3.51 & 1.95 & $1.83(1.28-2.62)$ \\
\hline SUA & Omphalocele & 5.32 & 3.06 & $1.78(1.33-2.39)$ \\
\hline Angioma & Hypospadias & 2.78 & 1.60 & $1.75(0.43-7.17)$ \\
\hline SUA & Truncus arteriosus & 3.62 & 2.13 & $1.73(1.21-2.46)$ \\
\hline SUA & Gastroschisis & 1.17 & 0.68 & $1.73(0.94-3.19)$ \\
\hline Foot 2-3 syndactyly & Preaxial limb reduction & 3.04 & 1.80 & $1.71(0.87-3.34)$ \\
\hline Macrosomia & Diaphragmatic hernia & 3.28 & 2.00 & $1.66(0.40-6.81)$ \\
\hline Macrosomia & Hydrocephaly & 11.48 & 7.24 & $1.66(0.75-3.66)$ \\
\hline Tags other & Cleft lip & 2.31 & 1.41 & $1.65(0.52-5.20)$ \\
\hline Inguinal hernia & Truncus arteriosus & 3.28 & 2.18 & $1.52(0.56-4.14)$ \\
\hline Angioma & Cephalocele & 2.78 & 1.90 & $1.47(0.36-6.02)$ \\
\hline Inguinal hernia & Cephalocele & 2.46 & 1.90 & $1.30(0.41-4.10)$ \\
\hline Inguinal hernia & Hydrocephaly & 9.02 & 7.24 & $1.27(0.68-2.36)$ \\
\hline SUA & Microtia & 5.11 & 4.10 & $1.26(0.94-1.70)$ \\
\hline SUA & VSD & 5.22 & 4.23 & $1.25(0.93-1.67)$ \\
\hline Preauricular pits & Microtia & 4.96 & 4.10 & $1.22(0.90-1.65)$ \\
\hline Foot 2-3 syndactyly & VSD & 5.07 & 4.25 & $1.20(0.71-2.03)$ \\
\hline SUA & Hydrocephaly & 8.52 & 7.20 & $1.20(0.95-1.52)$ \\
\hline Neonatal tooth & Postaxial polydactyly & 6.39 & 5.42 & $1.19(0.69-2.05)$ \\
\hline Neonatal tooth & Cleft palate & 5.94 & 5.10 & $1.18(0.67-2.08)$ \\
\hline
\end{tabular}

Abbreviations: ASD, atrial septal defect; $\mathrm{Cl}$, confidence interval; $\mathrm{M}-\mathrm{m}$, proportion of cases with the major defect among the total cases without the minor anomaly; $\mathrm{M}+\mathrm{m}$, proportion of cases with the major defect among the total cases with the minor anomaly (positive predictive value); OR, odds ratio; SUA, single umbilical artery; VSD, ventricular septal defect.

A further strength resided in the fact that ascertainment and reporting are performed by pediatricians who are specially trained in diagnosing and describing birth defects and who assure homogeneous data by following clearly defined rules.

\section{Clinical Features}

For several identified associations, the observed clinical features could be expected. For instance, high birth weight was observed in newborns with dyads involving macrosomia, low birth weight in newborns with all dyads involving inguinal hernia (which is common in preterm babies), and high mortality rates were observed in newborns with diaphragmatic hernia, a defect that is always severe, regardless of the associated $\mathrm{mA}$.

The birth weights of newborns with most dyads involving SUA were lower than the reference values, and all had higher mortality rates. Adverse neonatal outcomes, including death, 
Table 3 Concurrence risk between anomalies within dyads in first-degree relatives of a sample of newborns with isolated anomalies ascertained among 5,587,954 births between 1967-2007

\begin{tabular}{|c|c|c|c|c|c|c|}
\hline & & First-degree relat & & & & \\
\hline Anomaly & $N$ & Anomaly & 0 & $E$ & O/E & $p$ \\
\hline Microtia & 1,494 & Preauricular tags & 29 & 11.9 & 2.4 & $<0.001$ \\
\hline Preauricular tags & 12,288 & Microtia & 29 & 10.8 & 2.7 & $<0.001$ \\
\hline Microtia & 1,494 & Preauricular pits & 2 & 4.4 & 0.5 & 0.185 \\
\hline Preauricular pits & 4,536 & Microtia & 7 & 4.2 & 1.7 & 0.064 \\
\hline Truncus arteriousus & 1,242 & Inguinal hernia & 2 & 0.1 & 20.0 & $<0.001$ \\
\hline Inguinal hernia & 106 & $\mathrm{CHD}^{\mathrm{a}}$ & 0 & 0.1 & 0.0 & 0.905 \\
\hline Hypospadias & 1,962 & Angioma $^{a}$ & 6 & 7.3 & 0.8 & 0.406 \\
\hline Angioma & 778 & Hypospadias $^{\mathrm{a}}$ & 0 & 0.9 & 0.0 & 0.407 \\
\hline Cephalocele & 683 & Angioma $^{\mathrm{a}}$ & 1 & 0.3 & 3.3 & 0.037 \\
\hline Angioma & 778 & Cephalocele & 0 & 0.3 & 0.0 & 0.741 \\
\hline Truncus arteriousus & 1,242 & SUA & 0 & 0.7 & 0.0 & 0.497 \\
\hline SUA & 1,023 & $\mathrm{CHD}^{\mathrm{a}}$ & 5 & 4.7 & 1.1 & 0.332 \\
\hline Gastroschisis & 984 & SUA & 0 & 0.5 & 0.0 & 0.607 \\
\hline SUA & 1,023 & $\mathrm{AWD}^{\mathrm{a}}$ & 1 & 0.6 & 1.7 & 0.122 \\
\hline+2 & 2,504 & SUA & 0 & 1.5 & 0.0 & 0.223 \\
\hline+2 & 1,023 & $\mathrm{CHD}^{\mathrm{a}}$ & 5 & 4.7 & 1.1 & 0.332 \\
\hline Preaxial LR & 148 & SUA & 0 & 0.1 & 0.0 & 0.905 \\
\hline SUA & 1,023 & $\mathrm{LR}^{\mathrm{a}}$ & 1 & 0.1 & 10.0 & $<0.005$ \\
\hline Postaxial polydactyly & 7,915 & Neonatal Tooth & 1 & 2.6 & 0.4 & 0.267 \\
\hline Neonatal Tooth & 556 & Polydactylya & 2 & 2.9 & 0.7 & 0.446 \\
\hline
\end{tabular}

Abbreviations: AWD, abdominal wall defect; CHD, congenital heart defect; E, expected; LR, limb reduction; O, observed; p, Poisson cumulative probability; SUA, single umbilical artery; VSD, ventricular septal defect.

${ }^{a}$ Not further specified in affected relatives.

prematurity, low birth weight, and the presence of other associated anomalies have frequently been reported in newborns with SUA. ${ }^{13,14}$ Some authors have related the low birth weight to lower placental weight, ${ }^{7}$ however, the mechanism of the observed associations remains unknown for the majority of newborns with SUA.

\section{Preferential Associations between Minor and Major Defects}

Some of the identified associations are either well-known or can be explained on the hand of common developmental mechanisms or ascertainment and reporting biases.

Examples of observed associations that have been suggested to be present in syndromes were macrosomia + omphalocele in Beckwith syndrome and asymmetric cry + heart defects in Cayler syndrome. Their observation could be expected, as in the present work syndromes were not excluded.

SUA with anal or esophageal atresias are recognized as part of the VATER association, while the significant cooccurrence of SUA and microtia, has, to our knowledge, not been previously reported. However, overlapping of certain anomalies exists between VATER and the oculo auriculo vertebral (OAV) association, where microtia is a cardinal feature, ${ }^{15}$ and at least one case with OAV and SUA has been described. $^{16}$

The greater frequency of ambiguous genitalia among cases with anal atresia + SUA and microtia + SUA was mainly due to an associated sirenomelia or a persistent cloaca. While anal atresia is a component of both anomalies, microtia is not, reinforcing the suspicion that the relationship between microtia and SUA depends on the presence of other defects, such as those found in the OAV association.

The two most frequent mAs, SUA and preauricular tags, showed inverse association patterns. In accordance with other reports, ${ }^{17}$ SUA coexisted with several defects, whereas for preauricular tags no significant combination was observed except with microtia, an association that is obvious, as both are part of the same ear malformation. Similarly, the significant association between microtia and facial asymmetry could be expected, since both are consequences of a common developmental anomaly in newborns with hemifacial microsomia. ${ }^{18}$

Different clinical features (birth weight, mortality rates, and number of associated anomalies) in newborns with microtia with and without tags could indicate that both types of microtia represent different conditions, although incomplete descriptions omitting the presence of tags in severely affected newborns cannot be entirely ruled out. 
On the other hand, microtia with tags and microtia without SUA were proportional in their rates distribution of associated anomalies, and inverse rates of associated anomalies were observed for microtia with and without SUA (-Figs. 1 and 2). Both observations suggest that higher rates of associated anomalies are more related to the presence of SUA than to the absence of tags.

Other observed associations are most probably due to ascertainment biases. For instance, the apparent risk of having a major limb defect when a foot 2-3 syndactyly is present probably reflects the better description of any $\mathrm{mA}$ when a major defect in the same anatomical region has been detected.

\section{Minor Anomalies as Predictors}

A mA may lead to the diagnosis of its specifically associated major defect that is not visible or shows no immediate symptoms.

For instance, if a SUA is detected on prenatal ultrasound it could serve as a prenatal predictor of anal atresia which usually is not diagnosed prenatally and whose early detection may improve its postnatal management. ${ }^{19}$

On the other hand, mAs could also serve as predictors of specific major defects in other family members and this was observed for preauricular tags as predictor for microtia in relatives. Considering that microtia and tags are part of the same defect, their significant concurrence rates among relatives, consistent with previous reports, ${ }^{20}$ indicates that a substantial proportion of microtias are genetic in origin ${ }^{21}$ and that microtia can recur, even though with different degrees of severity, in other family members.

\section{Conclusions}

For the selected defects, and despite the large sample size and the exhaustive statistical analyses applied, no new or biologically meaningful association between a specific minor and major defect could be identified. The observed associations were either already well-known, or part of the same developmental anomaly, or most probably due to ascertainment biases.

No single $\mathrm{mA}$ with relevance as predictor for a major defect in the same newborn was observed. It could, however, be established that preauricular tags are capable of predicting the occurrence of microtia in other family members.

Based on the present results and on published reports, $1,3,4$ it can be concluded that rather than a specific anomaly it is the number of mAs what increases the risk for a major birth defect coexisting in the same newborn.

\section{Acknowledgments}

This work was partially supported by the National Council for Scientific Research (CONICET): grants number 0257, and Agencia Nacional de Promoción Científica y Tecnológica 0429, and the Scientific Research Commission of Buenos Aires (CICPBA), Argentina.

\section{References}

1 Marden PM, Smith DW, McDonald MJ. Congenital Anomalies in the newborn infant, including minor variations. A study of 4,412 babies by surface examination for anomalies and buccal smear for sex chromatin. J Pediatr 1964;64:357-371

2 Merks JH, van Karnebeek CD, Caron HN, Hennekam RC. Phenotypic abnormalities: terminology and classification. Am J Med Genet A 2003;123A(3):211-230

3 Méhes K, Mestyán J, Knoch V, Vincellér M. Minor malformations in the neonate. Helv Paediatr Acta 1973;28(5):477-483

4 Leppig KA, Werler MM, Cann CI, Cook CA, Holmes LB. Predictive value of minor anomalies. I. Association with major malformations. J Pediatr 1987;110(4):531-537

5 Holmes LB, Kleiner BC, Leppig KA, Cann CI, Muñoz A, Polk BF. Predictive value of minor anomalies: II. Use in cohort studies to identify teratogens. Teratology 1987;36(3):291-297

6 Waldrop MF, Bell RQ McLaughlin B, Halverson CF Jr. Newborn minor physical anomalies predict short attention span, peer aggression, and impulsivity at age 3 . Science 1978;199(4328): 563-565

$7 \mathrm{Mu}$ SC, Lin CH, Chen YL, Sung TC, Bai CH, Jow GM. The perinatal outcomes of asymptomatic isolated single umbilical artery in fullterm neonates. Pediatr Neonatol 2008;49(6):230-233

8 Meggyessy V, Méhes K. Association of supernumerary nipples with renal anomalies. J Pediatr 1987;111(3):412-413

9 Castilla EE, Orioli IM. ECLAMC: the Latin-American collaborative study of congenital malformations. Community Genet 2004;7(23):76-94

10 Opitz JM. Heterogeneity and minor anomalies. Am J Med Genet 2000;91(4):254-255

11 Opitz JM. Invited editorial comment: study of minor anomalies in childhood malignancy. Eur J Pediatr 1985;144:252-254

12 Tsai FJ, Tsai CH, Peng CT, Wu JY, Lien CH, Wang TR. Different race, different face: minor anomalies in Chinese newborn infants. Acta Paediatr 1999;88(3):323-326

13 Rinehart BK, Terrone DA, Taylor CW, Isler CM, Larmon JE, Roberts WE. Single umbilical artery is associated with an increased incidence of structural and chromosomal anomalies and growth restriction. Am J Perinatol 2000;17(5): 229-232

14 Pierce BT, Dance VD, Wagner RK, Apodaca CC, Nielsen PE, Calhoun BC. Perinatal outcome following fetal single umbilical artery diagnosis. J Matern Fetal Med 2001;10(1):59-63

15 Källén K, Robert E, Castilla EE, Mastroiacovo P, Källén B. Relation between oculo-auriculo-vertebral (OAV) dysplasia and three other non-random associations of malformations (VATER, CHARGE, and OEIS). Am J Med Genet A 2004;127A(1):26-34

16 Haratz K, Vinkler C, Lev D, Schreiber L, Malinger G. Hemifacial microsomia with spinal and rib anomalies: prenatal diagnosis and postmortem confirmation using 3-D computed tomography reconstruction. Fetal Diagn Ther 2011;30(4):309-313

17 Martínez-Frías ML, Bermejo E, Rodríguez-Pinilla E, Prieto D; ECEMC Working Group. Does single umbilical artery (SUA) predict any type of congenital defect? Clinical-epidemiological analysis of a large consecutive series of malformed infants. Am J Med Genet $A$ 2008;146A(1):15-25

18 Keogh IJ, Troulis MJ, Monroy AA, Eavey RD, Kaban LB. Isolated microtia as a marker for unsuspected hemifacial microsomia. Arch Otolaryngol Head Neck Surg 2007;133(10):997-1001

19 Gornall AS, Kurinczuk JJ, Konje JC. Antenatal detection of a single umbilical artery: does it matter? Prenat Diagn 2003;23(2): 117-123

20 Klockars T, Suutarla S, Kentala E, Ala-Mello S, Rautio J. Inheritance of microtia in the Finnish population. Int J Pediatr Otorhinolaryngol 2007;71(11):1783-1788

21 Alasti F, Van Camp G. Genetics of microtia and associated syndromes. J Med Genet 2009;46(6):361-369 